Pick's disease confined to the parietal lobes is uncommon, but when it is, the distribution corresponds to that indicated in this case.

Probably, therefore, Darius Clayhanger, and by inference Enoch Bennett, suffered from Pick's disease. Was the disorder familial ? Reported cases most commonly suggest an autosomal dominant inheritance. The evidence in the case of the Bennett family is unimpressive however. Dorothy Cheston Bennett expressed fears that a similar disease was affecting Arnold Bennett ( $M$ Drabble, personal communication), a concern he shared towards the end of his life, ${ }^{2}$ but his fournals nowhere support the possibility.

Margaret Drabble has suggested that a similar disease killed two of his sisters, ${ }^{12}$ but has indicated (personal communication) that the evidence for this was based on family gossip alone.

Russell Brain claimed that dressing apraxia, as a symptom, had not been specifically described. ${ }^{13}$ Surprisingly, he seemed unaware of the French cases, and clearly he was not a devotee of Arnold Bennett. Had he read Clayhanger, he would have had access to a masterly account of the syndrome and at the same time would have partaken of one of the masterpieces of twentieth-century fiction.

\section{References}

' Bennett A. Clayhanger. London: Methuen, 1910.
2 Barker D. Writer by trade. A view of Arnold Bennett. London: George Allen and Unwin Ltd, 1966.

${ }^{3}$ Flower N, ed. The journals of Arnold Bennett 1911-1921. London: Cassell, 1932. (20 November 1914).

${ }^{4}$ Hepburn J, ed. Letter to George Sturt, 13 February 1900. In: Letters of Arnold Bennett. Vol 2, 1889-1951. London: Oxford University Press, 1968.

${ }^{5}$ Hepburn J, ed. Letter to George Sturt, 10 February 1901. In: Letters of Arnold Bennett. Vol 2, 1889-1915. London: Oxford University Press, 1968

'Hepburn J, ed. Letter to Thomas Lloyd Humberstone, 14 May 1901. In: Letters of Arnold Bennett. Vol 2, 1889-1915. London: Oxford University Press, 1968.

${ }^{7}$ Jackson H. Case of large cerebral tumour without optic neuritis, and with left hemiplegia and imperception. Royal London Ophthalmic Hospital Reports $1876 ; 8: 434-44$.

${ }^{\rtimes}$ Wendenburg K. Ein tumor des rechten hinterhauptlappens mit ungewöhnlichen klinischen begleit-erscheinungen. Monatsschrift für Psychiatrie und Neurologie. $1909 ; 25: 428-40$.

${ }^{9}$ Hécaen $\mathrm{H}$, Ajuriaguerra $\mathrm{J}$ de. L'apraxie de l'habillage. Ses rapports avec la planotopokinésie et les troubles de la somatognosie. L'Encéphale 1945; 35: 113-44.

1" Lhermitte J, Massary J de, Kyriaco N. Le rôle de la pensée spatiale dans l'apraxie. Rev Neurol (Paris) 1928;35(2):895-903.

"Lhermitte J, Trelles JO. Sur l'apraxie pure constructive. Les troubles de la pensée spatiale et de la somatognosie dans l'apraxie. L'Encéphale $1933 ; 28: 413-44$.

1.2 Drabble M. Arnold Bennett. A biography. London: Weidenfeld and Nicolson Ltd, 1974.

13 Brain WR. Visual disorientation with special reference to lesions of the right cerebral hemisphere. Brain 1941 ;64:244-72.

(Accepted 25 fune 1981)

\title{
Arthritis in Saxon and mediaeval skeletons
}

\author{
JULIET ROGERS, IAIN WATT, PAUL DIEPPE
}

\begin{abstract}
Examination of 400 Saxon, Romano-British, and mediaeval skeletons from seven archaeological excavations in the west of England showed an unexpectedly high incidence of osteoarthritis and osteophytosis. Three skeletons had evidence of an erosive peripheral arthritis-one with probable gout, one probable psoriatic arthropathy, and one with possible rheumatoid arthritis. The pattern and types of rheumatic disease, and the resultant disability, were apparently different. An exuberant form of large joint osteoarthritis was common and rheumatoid arthritis and similar diseases rare.
\end{abstract}

\section{Introduction}

Paleopathology, the study of diseases in antiquity, may provide important information on changing patterns of disease and give clues to aetiology and prevention. Skeletons give a chance to document bone and joint disease in particular, and are a major source of paleopathological data. ${ }^{12}$

The antiquity of many rheumatological diseases, including osteoarthritis, ankylosing spondylitis, and gout, is well estab-

\footnotetext{
University Department of Medicine and Department of Radiodiagnosis, Bristol Royal Infirmary, Bristol BS2 8HW

JULIET ROGERS, MB, CHB, paleopathologist

IAIN WATT, MRCP, FRCR, consultant radiologist

PAUL DIEPPE, BSC, MRCP, senior lecturer in rheumatology
}

lished, ${ }^{3}$ but rheumatoid arthritis may be of recent origin. ${ }^{4} \mathrm{~s}$ Furthermore, the pattern and severity of these diseases are thought to vary in different societies and may be changing. ${ }^{6} 7$ We have recently had the opportunity to study some 400 Saxon, Romano-British, and mediaeval skeletons and to document evidence of arthritic changes, which has provided a wealth of new information on the paleopathology of rheumatic diseases.

\section{Collection of material}

The skeletons came from seven separate archaeological excavations in the west of England. About 250 were mediaeval (thirteenth to fifteenth centuries) and came from Taunton Priory, Bristol Greyfriars, and Bath Orange Grove. The remainder were either Romano-British (first to fourth centuries) or Saxon (ninth to eleventh centuries); the 50 Saxon skeletons came from Trowbridge, in Wiltshire.

After excavation, the skeletons were lifted, washed, and repaired where necessary. The presence of one of us (JR) on the site helped to minimise the risk of damage, and allowed important in-situ observations of the material to be made. The excavations were from lay cemeteries, and the adult skeletons examined had a roughly equal sex incidence.

\section{Examination}

The skeletons were temporarily removed for further examination, and all were assessed by a paleopathologist (JR). Many specimens also underwent radiography and examination by a radiologist (IW) and a rheumatologist (PD). Photographs and radiographs of the more interesting cases were kept as a permanent record.

The estimated age, sex, stature, and dental state of each skeleton were noted as were the presence or absence of bone and arthritic changes. 


\section{Findings}

The best preserved skeletons were either mediaeval (about 150) or Saxon (50). Most were of young adults with an estimated age range of from 20 to 50 years. There was no apparent pathological abnormality in $30 \%$. There was evidence of infection (osteomyelitis or periostitis) in $3.5 \%$ and bony injury in $8 \%$; the latter included one example of a sword cut. There was no evidence of tuberculosis in the 400 complete skeletons examined, although one disarticulated set of vertebral bodies did show the typical radiological features of spinal tuberculosis.

The commonest changes were arthritic. Some spinal changes were seen in about half the skeletons, and nearly $40 \%$ had abnormalities of the peripheral joints-predominantly osteoarthritic or osteophytic changes in large joints. Osteophytes alone were not uncommon, but evidence of an altered bony contour or radiological evidence of bone sclerosis and cysts, or a combination of these, were frequent, and taken to be unequivocal evidence of osteoarthritis. ${ }^{8}$ Small joint lesions were less common, although not all the bones of the hands and feet were always available. Only three skeletons were thought to have evidence of an erosive arthropathy, and in each case a careful radiological and
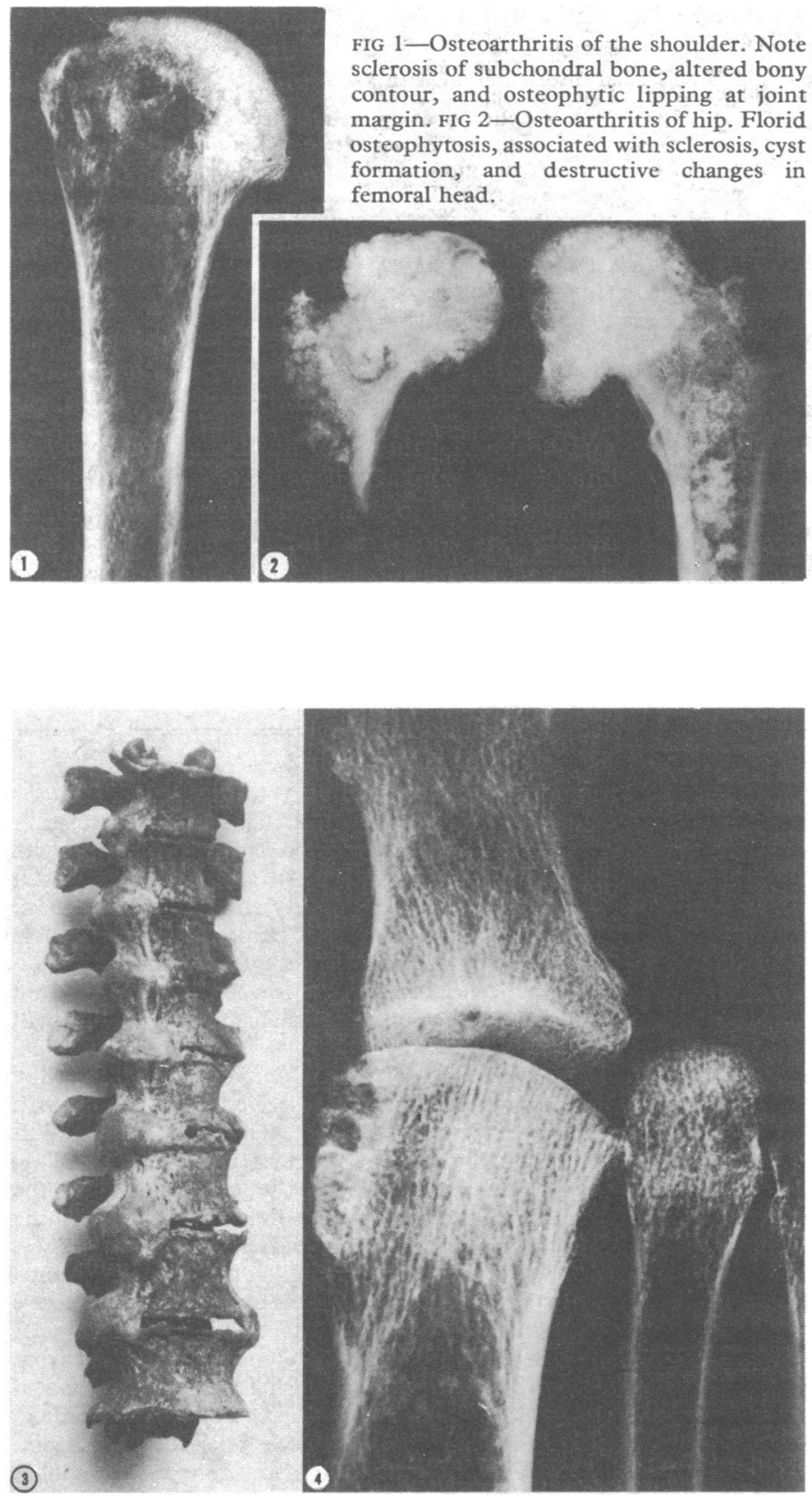

FIG 3-Idiopathic skeletal hyperostosis. This specimen, belonging to a Saxon bishop, shows typical osteophytic changes on right side of thoracolumbar vertebrae. FIG 4--Gout. Para-articular erosions, with sclerotic bone margins are typical of gout at first metatarsophalangeal joint.
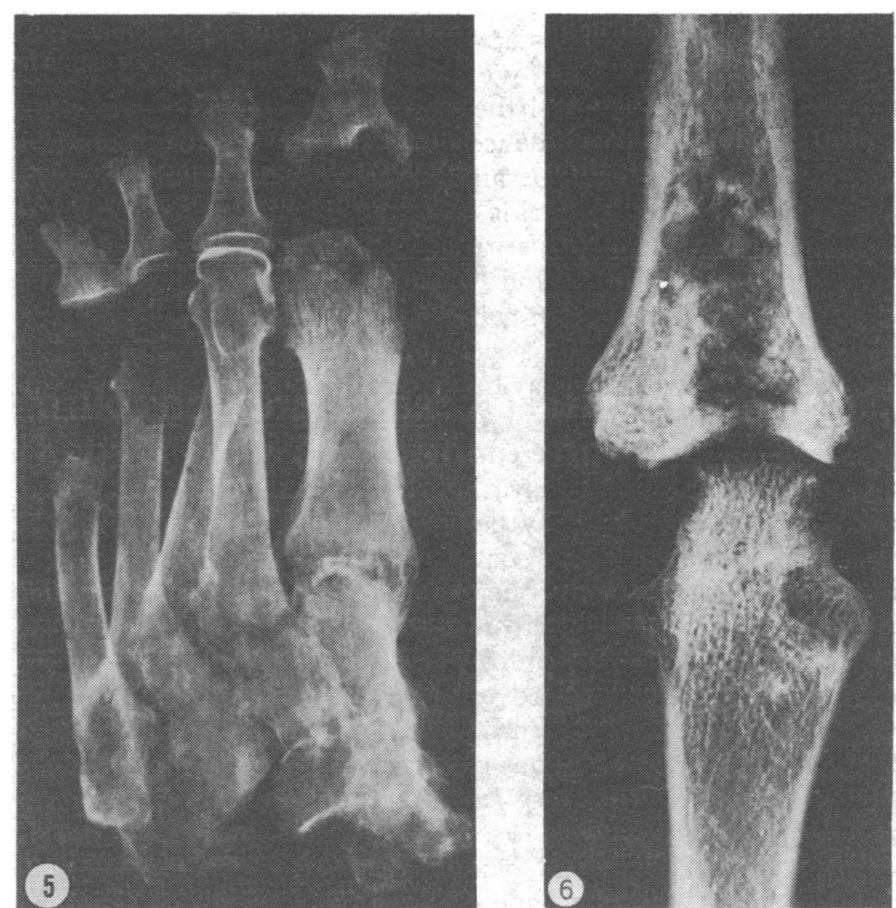

FIG 5-Psoriatic arthropathy ? Note ankylosis of midtarsal joints and destruc tive changes in terminal phalanx of big toe. FIG 6-Rheumatoid arthritis Peri-articular erosions around this metacarpophalangeal joint are compatible with a diagnosis of rheumatoid arthritis, although another erosive arthropathy cannot be excluded.

pathological examination allowed them to be assigned a probable diagnostic category.

Large joint osteoarthritis-Hip and shoulder osteoarthritis were both common. The 50 Saxon skeletons, however, had an even higher incidence of advanced changes (shoulder $24 \%$, hip $28 \%$ ) than the 150 mediaeval specimens (shoulder $12 \%$, hip $10 \%$ ), and exuberant osteophytosis of the shoulder or hip was a surprisingly frequent finding (figs 1 and 2).

Spinal disease-Spinal osteophytosis of both the vertebrae and apophyseal joints was frequent (47\% Saxon skeletons, $49 \%$ mediaeval). Associated bone sclerosis was often present, indicative of osteoarthritis. Five examples of idiopathic skeletal hyperostosis (Forrestier's disease) were noted. One was the skeleton of Bishop Giso, the last Saxon bishop of Wells Cathedral (fig 3). One example of an erosive sacroiliitis was seen; the changes were asymmetrical and associated with fluffy periosteal changes in the pelvis, suggesting the possibility of Reiter's disease or psoriasis rather than ankylosing spondylitis.

Peripheral erosive arthropathies-Three examples were found. The first was seen in the metatarsophalangeal joint of a Saxon man from Trowbridge (fig 4); the erosions are typical of gout. ${ }^{10}$ The other two cases were possible cases of rheumatoid arthritis and therefore of particular interest. One came from a thirteenth-century man who was buried with the knees flexed (not a burial custom at that time). There was widespread arthritis, with ankylosis of some interphalangeal joints, and erosive "cup and pencil" deformities affecting distal as well as proximal joints, indicative of psoriatic arthropathy ${ }^{11}$ (fig 5). The other cases showed erosive changes in the metacarpal phalangeal joints and some lesions in the knees, hips, and shoulders. The radiological erosions and geodes suggest rheumatoid arthritis ${ }^{11}$ (fig 6).

\section{Discussion}

Many skeletal surveys have been hampered by poor material, a lack of adequate description or radiological analysis, and, particularly, by a lack of discrimination between the different rheumatological diseases. We were helped by having a paleopathologist on site, the use of radiological facilities and interpretation, and a rheumatological opinion.

Many skeletons were incomplete or damaged; nevertheless, a large number of observations of arthritic disease were possible. 
The age range of $20-50$ years, with a probable mean of about 40 , would be unlikely to yield many changes (other than in the spine) of English people today. ${ }^{12} \mathrm{We}$ cannot know how representative these skeletons are, although they were from typical lay cemeteries, and had an equal sex incidence.

Osteoarthritis and exuberant osteophytosis were both common. Although osteoarthritis occurs in all species, ages, and races, ${ }^{3}$ the pattern and severity of the changes were unexpected. The relatively small Saxon sample had a particularly high incidence of shoulder disease, a joint rarely found to be affected by osteoarthritis in current series. ${ }^{12}{ }^{13}$ The occupation of these people is unknown, and may be relevant, although the frequency of this proximal pattern of osteoarthritis in relatively young people suggests that a different subset of osteoarthritis, or even a different disease, might have been affecting these people. The exuberant osteophytes may be linked with the tendency to get vertebral hyperostosis, as both may be part of an inherited tendency to form excess bone. ${ }^{14}$

The low incidence of erosive arthropathies may not be unexpected in a group of young adults; and until more skeletons can be examined it is hard to say whether the incidence was appreciably below that seen now. The case of gout was similar to those described in various other skeletons. ${ }^{15}$ The radiological changes in the second case seem classical for psoriatic arthropathy, ${ }^{11}$ although this is, to our knowledge, the first reported case on paleopathological evidence. A "seronegative" erosive arthropathy of psoriatic type cannot be ruled out in the third case either, although rheumatoid arthritis seems more likely. Some authors have been struck by the relative paucity of reports of rheumatoid arthritis in paleopathological publications, ${ }^{45}$ although others have pointed to a few isolated possible cases and have noted the difficulty in obtaining a good examination of the small joints of the hands and feet. ${ }^{16-18}$ Our findings argue against the case for rheumatoid arthritis being a recent disease arising from a new virus. ${ }^{516}$

Although we hope to gain more complete data from a further 1500 skeletons awaiting examination, comparisons with recent epidemiological or radiological surveys cannot yet be made. Our survey suggests that arthritis was as big a problem to our ancestors as it is now. The pattern and types of rheumatic disease, however, and the disability they caused, were apparently quite different. An exuberant form of large joint osteoarthritis was common, and rheumatoid arthritis and similar diseases rare in our relatively recent past.

We thank the Arthritis and Rheumatism Council for financial support.

\section{References}

' Steinbock RT. Paleopathological diagnosis and interpretation. Springfield, Illinois: C C Thomas, 1976.

2 Bourke JB. A review of the paleopathology of the arthritic diseases. In: Brothwell D, Sandison AT, eds. Diseases in antiquity. Springfield, Illinois: C C Thomas, 1967:352-70.

${ }^{3}$ Kaish RS, McCarthy JD. Archaeology and arthritis. Arch Intern Med $1960 ; 105: 640-4$.

4 Short CL. The antiquity of rheumatoid arthritis. Arthritis Rheum 1974; 17:193-205.

5 Buchanan WW, Murdoch RM. Hypothesis: that rheumatoid arthritis will disappear. $\mathcal{F}$ Rheumatol $1979 ; 6: 324-9$.

${ }^{6}$ Valkenberg HA. Pattern of rheumatoid disease in society: change or disappearance. Scand $\mathcal{f}$ Rheumatol 1976;Suppl 5:89-95.

${ }^{7}$ Shulman LE. Are there changing patterns of rheumatic diseases? In: Dumonde DC, ed. Infection and immunology in the rheumatic diseases. Oxford: Blackwell, 1976

${ }^{8}$ Kellgren JH, Lawrence JS. Radiological assessment of osteoarthritis. Ann Rheum Dis 1957;16:494-502.

${ }^{9}$ McEwen C, Di Tata D, Lingg C, Porini A, Good A, Rankin T. Ankylosing spondylitis and spondylitis accompanying ulcerative colitis, regional enteritis, psoriasis and Reiter's disease. Arthritis Rheum 1971;14:291-318.

10 Martel W. Overhanging margin of bone: roentgeologic manifestation of gout. Radiology 1968;91:755-65.

11 Watt I, Middlemiss H. Radiology in rheumatic diseases. Clinics in Rheumatic Diseases 1976;2:93-127.

12 Lawrence JS Rheumatism in populations. London: Heinemann, 1977.

${ }^{13}$ Huskisson EC, Dieppe PA, Tucker AK, Cannell LB. Another look at osteoarthritis. Ann Rheum Dis 1979;38:423-9.

14 Utsinger PD, Resnick D, Shapiro R. Diffuse skeletal abnormalities in Forrester's disease. Arch Intern Med 1976;136:763-8.

${ }^{15}$ Copeman WC. A short history of the gout. Berkeley: University of California Press, 1964.

16 Wood PHN. Is rheumatoid arthritis a recent disease ? In : Dumonde DC, ed. Infection and immunology in the rheumatic diseases. Edinburgh: Blackwell, 1976.

${ }^{17}$ Caighey DE. The arthritis of Constantine IX. Ann Rheum Dis 1974;33: $77-9$.

18 Sturrock RD, Sharma JN, Buchanan WW. Evidence of rheumatoid arthritis in ancient India. Arthritis Rheum 1977;20:42-4.

(Accepted 19 May 1981) 